\title{
Beticolins, Nonpeptidic, Polycyclic Molecules Produced by the Phytopathogenic Fungus Cercospora beticola, as a New Family of lon Channel-Forming Toxins
}

\author{
Cyril Goudet, ${ }^{1}$ Marie-Louise Milat, ${ }^{2}$ Hervé Sentenac, ${ }^{1}$ and Jean-Baptiste Thibaud ${ }^{1}$ \\ ${ }^{1}$ Laboratoire de Biochimie et Physiologie Moléculaire des Plantes, CNRS URA 2133/ENSA-M/INRA/UM2, 2 , \\ Place Pierre Viala, 34060 Montpellier Cedex 1, France; ${ }^{2}$ Laboratoire de Phytopharmacie et Biochimie \\ des Interactions Cellulaires, UA 692 INRA/Université de Bourgogne, BV 1540, 21034 Dijon Cedex, \\ France \\ Accepted 19 October 1999.
}

Beticolins are toxins produced by Cercospora beticola, a phytopathogenic fungus responsible for the leaf spot disease of sugar beet. They form a family of 20 nonpeptidic compounds (named BO to B19) that share the same polycyclic skeleton but differ by isomeric configuration (orthoor para-) and by a variable residue $R$ (bridging two carbons in one of the six cycles). It has been previously shown that $\mathrm{BO}$ assembles itself into a multimeric structure and forms ion channels into planar lipid bilayers (C. Goudet, A.-A. Véry, M.-L. Milat, M. Ildefonse, J.-B. Thibaud, H. Sentenac, and J.-P. Blein, Plant J. 14:359-364, 1998). In the present work, we investigate pore formation by three $o r$ tho-beticolins, B0, B2, and B4, and their related (i.e., same $R$ ) para-isomers, B13, B1, and B3, respectively, using planar lipid bilayers. All beticolins were able to form ion channels with multiple conductance states, although the type of cyclization (ortho- or para-) and residue $(R)$ result in variations of channel conductance and ionic permeability, respectively. Channel formation by beticolins is likely to be involved in the biological activity of these toxins.

The genus Cercospora is a large group of fungal plant pathogens that cause disease worldwide on important crop species such as corn, coffee, tobacco, soybean, banana, and sugar beet. Due to their broad host range and worldwide distribution, Cercospora species are of major economic impact. Cercospora beticola Sacc. is the phytopathogenic fungus responsible for the leaf spot disease of sugar beet (Beta vulgaris L.). In vitro, this fungus produces a toxin named cercosporin and a family of other toxins named beticolins that are thought to be involved in its pathogenicity (Ballio 1991).

Cercosporin is a perylenequinone secondary metabolite (Lousberg et al. 1971; Yamazaki and Ogawa 1972) with a non-host-specific toxicity (Balis and Payne 1971; Fajola 1978; Daub and Ehrenshaft 1993). Toxic effects of cercosporin on plant cells are well documented. Toxicity is due to the pro-

Corresponding author: Jean-Baptiste Thibaud; Telephone: +33 499612 609; Fax: +33 467525 737; E-mail: thibaud@ensam.inra.fr duction of oxygen active forms by light-activated cercosporin (Daub 1982; Daub and Hangarter 1983; Dobrowolski and Foote 1983; Hartman et al. 1988), leading to membrane lipid peroxidation (Knox and Dodge 1985).

Beticolins form a family of 20 nonpeptidic compounds, named beticolin-0 to -19 (B0 to B19). They share the same polycyclic skeleton with a chlorine atom and partially hydrogenated anthraquinone and xanthone, but differ by isomeric configurations (ortho- or para-) and by a variable residue $(R)$ bridging $\mathrm{C} 11^{\prime}$ and $\mathrm{C} 14^{\prime}$ (Fig. 1) (Milat et al. 1992; Prangé et al. 1997). Beticolins are non-host-specific phytotoxins that cause a broad range of cytotoxic effects. In planta, beticolins induce dramatic loss of solutes such as amino acids and $\beta$ cyanin from root tissues (Schlösser 1971; Macri and Vianello 1979). These non-host-specific toxins inhibit ATP-dependent $\mathrm{H}^{+}$transport in pea stem (Macri et al. 1983) and corn root (Blein et al. 1988). On tobacco cells, beticolins cause membrane depolarization (Gapillout et al. 1996). Biophysical studies showed that beticolins are able to chelate $\mathrm{Mg}^{2+}$ and to

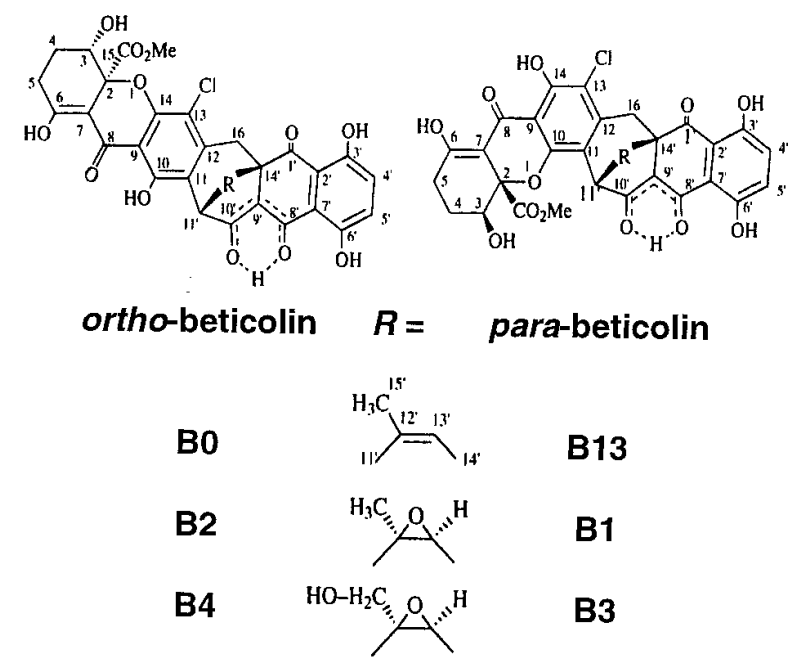

Fig. 1. Structure of ortho- and para-beticolins. 
form (B-Mg) dimeric complexes (Mikes et al. 1994a). These complexes have a higher affinity for membranes than beticolin monomer (Mikes et al. 1994b; Gomès et al. 1996b). In addition to their effects on membrane transports, beticolins exhibit an antibiotic activity (Schlösser 1962). In vitro, beticolins also display an $\mathrm{O}_{2}^{-}$scavenging activity (Rustérucci et al. 1996) and an anti-proliferative effect on rat adrenocortical cell lines (Ding et al. 1996).

It was recently demonstrated that beticolin- 0 molecules are able to assemble themselves in the presence of $\mathrm{Mg}^{2+}$ and to form weakly cationic selective channels that strongly increase membrane conductance (Goudet et al. 1998). In the present work, we investigate ion channel formation by six toxins of the beticolin family (B0, B13, B2, B1, B4, and B3) with planar lipid bilayer and voltage clamp techniques, which provide a powerful model (Kagan and Sokolov 1994). The chosen beticolins constitute three pairs of ortho/para isomers (Fig. 1). We demonstrate that any of these toxins can form ion channels displaying multiple conductance states. These channels are compared in terms of voltage dependence, conductance in different salt media, ionic selectivity, and $\mathrm{Mg}^{2+}$ sensitivity. The results are discussed in terms of the structure-activity relationship. It is likely that the deleterious properties of beticolins involve this pore-forming property, as demonstrated for syringomycin, a necrosis-inducing lipopeptide toxin secreted by the phytopathogenic bacteria Pseudomonas syringae (Hutchison et al. 1995; Feigin et al. 1996; Bender et al. 1999; Dalla Serra et al. 1999b).

\section{RESULTS}

Ion channel activity of beticolins.

A few minutes after addition of $10 \mu \mathrm{M}$ beticolin (B0, B13, $\mathrm{B} 1, \mathrm{~B} 2, \mathrm{~B} 4$, or $\mathrm{B} 3)$ to the cis medium, discrete current transi-
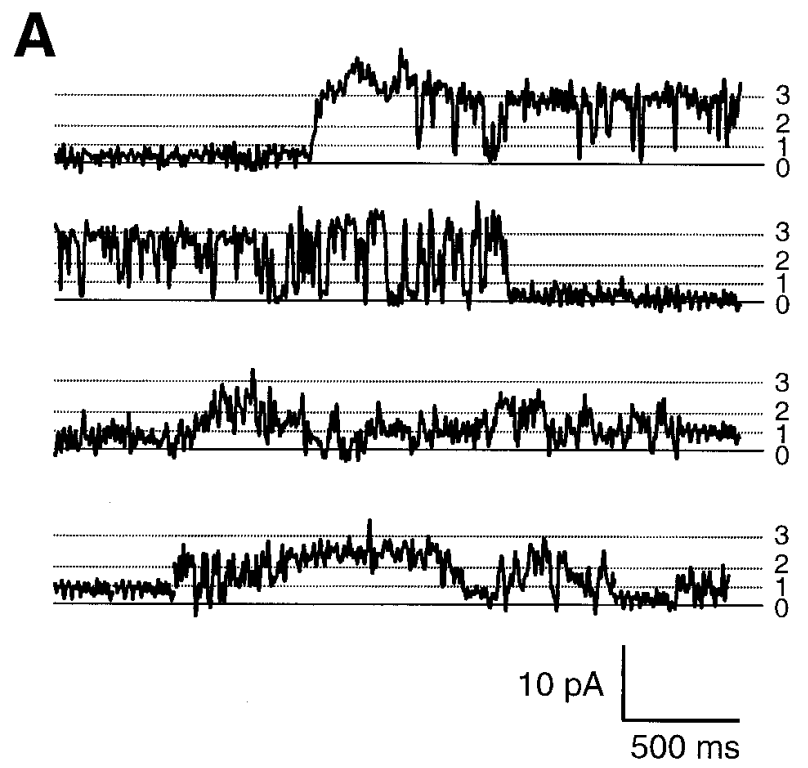

tions were recorded. Figure 2 shows examples of 12-s-long current records displaying different amplitude levels observed after addition of $10 \mu \mathrm{M}$ B4 (Fig. 2A) or B3 (Fig. 2B) to the cis medium. Similar "single channel" events were observed for other forms of beticolin (not shown, but see Goudet et al. 1998 for B0). In standard solution, the free $\mathrm{Mg}^{2+}$ concentration was estimated to be $1 \mu \mathrm{M}$. When $50 \mu \mathrm{M} \mathrm{MgCl}_{2}$ was added into the cis medium the beticolin-induced current increased and a macroscopic current could be recorded (not shown), as previously reported for B0 (Goudet et al. 1998). In the present study, we focused on unitary current analysis.

\section{Multiple conductance values of beticolin channels.}

In conditions allowing recording of unitary current (i.e., 1 $\mu \mathrm{M} \mathrm{Mg}^{2+}$ ), all beticolin channels displayed at least three conducting states. For any beticolin, current traces similar to those shown in Figure 2 were obtained at different voltages from -120 to $+120 \mathrm{mV}$, allowing current-voltage (i-V) relationships of the first three conducting levels formed by each of these toxins to be determined (Fig. 3). The relationships are all approximately linear and cross the axes close to the origin. Data in Figure 3 are from records of experiments with symmetrical cis/trans $200 \mathrm{mM} \mathrm{NaCl}$ standard solutions. Similar results were obtained when $\mathrm{NaCl}$ was replaced by either $\mathrm{KCl}$ or $\mathrm{LiCl}$ (not shown, but see Table 1). Numeric values of conductance for the first three conducting levels of each studied beticolin are given in Table 1. Whatever the beticolin and the ionic conditions, the conductance of level three was approximately twice that of level two, itself being approximately twice that of level one. Whatever the ortho/para isomer pair considered, the conductance induced by the para-isomer was 20 to $30 \%$ higher than that induced by the ortho-isomer. The B0/B13 pair displayed lower conductance than the B4/B3 pair, which itself produced less conductance than the B2/B1 pair.

B
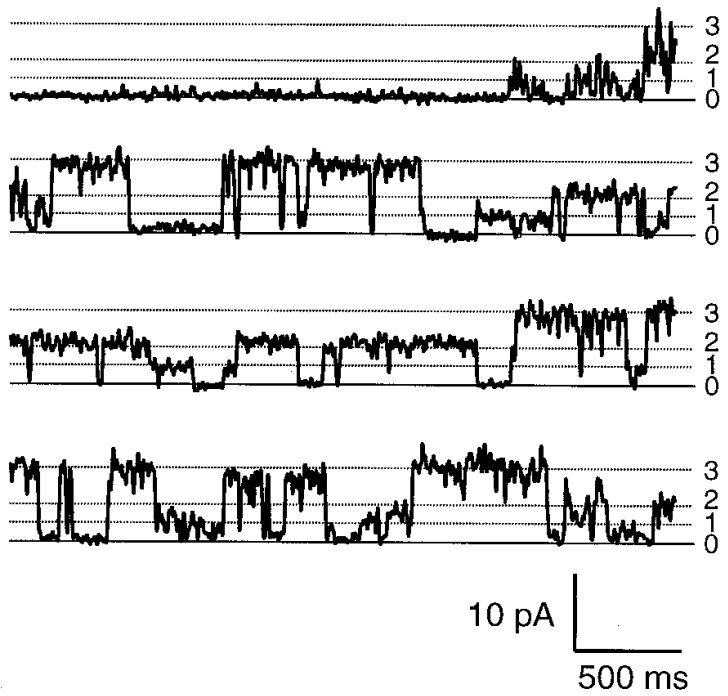

Fig. 2. Unitary currents of different amplitudes induced by beticolins through a planar lipid bilayer. Representative trace of channel activity recorded at $+120 \mathrm{mV}$ in standard symmetric solutions a few minutes after addition of $10 \mu \mathrm{M}$ concentrations of (A) ortho-B4 or (B) para-B3 toxin to the cis solution. Both cis and trans standard solutions contained $200 \mathrm{mM} \mathrm{NaCl}, 0.44 \mathrm{mM} \mathrm{MgCl}_{2}, 1 \mathrm{mM}$ EDTA, and $10 \mathrm{mM}$ HEPES ( $N$-2-hydroxyethylpiperazine- $N^{\prime}-2-$ ethanesulfonic acid)- $\mathrm{KOH}$ ( $\mathrm{pH}$ 7.4). The free $\mathrm{Mg}^{2+}$ concentration was estimated to be $1 \mu \mathrm{M}$. Data were recorded at $2 \mathrm{kHz}$ and filtered at $50 \mathrm{~Hz}$. Current of the closed (0) state is indicated by the solid line. Dotted lines (marked by 1,2, and 3) show the three different discrete current amplitude levels determined from an amplitude histogram. 
Conductance of beticolin-formed channels thus appeared to depend on both the type of isomerization and the type of $R$ residue.

\section{Ionic selectivity.}

The cation/anion selectivity of beticolin channels was determined by measuring the current reversal potential (Erev) in $500 \mathrm{mM} / 100 \mathrm{mM}$ (cis/trans) concentration gradients of chloride salts $(\mathrm{KCl}, \mathrm{NaCl}$, or $\mathrm{LiCl})$. In these conditions, the equilibrium potentials of $\mathrm{Cl}^{-}$ions and that of the accompanying cation were close to -40 and $+40 \mathrm{mV}$ respectively. For each tested beticolin, Erev values slightly depended on the chloride salt used, revealing some ionic selectivity. However, in a given salt gradient, the values were roughly the same for the first three conductance levels (exact individual values were found within a $3-\mathrm{mV}$ range around the average value). Erev values were positive, indicating selectivity for cations versus $\mathrm{Cl}^{-}$. From these data, $\mathrm{P}_{\mathrm{X}} / \mathrm{P}_{\mathrm{Cl}}$ permeability ratios and thereby $\mathrm{P}_{\mathrm{X}} / \mathrm{P}_{\mathrm{K}}$ ratios ( $X$ being $\mathrm{Na}, \mathrm{Li}$, or $\mathrm{K}$ ) were derived with the Goldman-Hodgkin-Katz equation (Table 2). Except for B4 and $B 3$, all the $P_{X} / P_{K}$ and $G_{X} / G_{K}$ ratio values were $<1$. Thus, $B 4$ and $\mathrm{B} 3$ showed a slight selectivity for $\mathrm{Na}^{+}$or $\mathrm{Li}^{+}$versus $\mathrm{K}^{+}$,
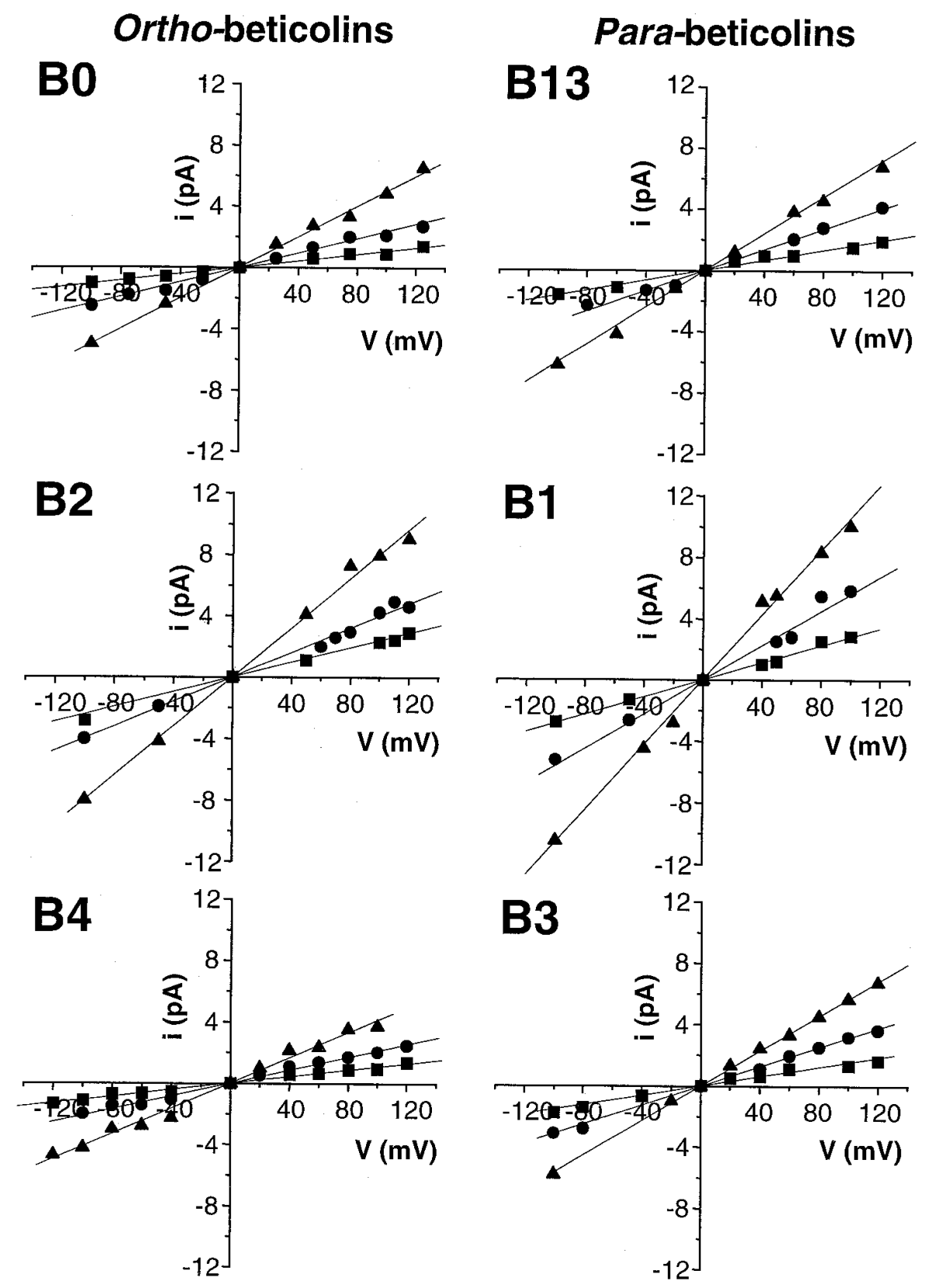

Fig. 3. Current-voltage relationship of ortho-beticolins B0, B2, and B4 and corresponding para-beticolins B13, B1, and B3. Current amplitude of level 1,2 , and 3 is represented by $\mathbf{\square}, \mathbf{O}, \mathbf{\Delta}$, respectively. Amplitude values of the current (i; mean value; $n \geq 3$ experiments) for each beticolin are plotted against the voltage value (V) at which they have been recorded. Beticolin concentration was $10 \mu \mathrm{M}$. Both cis and trans side medium contained $200 \mathrm{mM}$ $\mathrm{NaCl}, 0.44 \mathrm{mM} \mathrm{MgCl} 2,1 \mathrm{mM}$ EDTA, and $10 \mathrm{mM}$ HEPES ( $N$-2-hydroxyethylpiperazine- $N{ }^{\prime}$-2-ethanesulfonic acid)- $\mathrm{KOH}$ (pH 7.4). Free $\mathrm{Mg}^{2+}$ concentration was estimated to be $1 \mu \mathrm{M}$. 
while the other studied beticolins showed a slight selectivity for $\mathrm{K}^{+}$versus $\mathrm{Na}^{+}$and $\mathrm{Li}^{+}$.

\section{DISCUSSION}

A new family of ion channel-forming toxins.

Addition of $10 \mu \mathrm{M}$ concentrations of beticolins (B0, B13, B2, B1, B4, or B3) induced discrete current transitions, similar to those occurring upon opening and closing of ion channels, indicating that all six beticolins are able to form ion channels, as previously demonstrated for B0 (Goudet et al. 1998).

It is therefore likely that all beticolins are able to form ion channels, due to the relative similarity of their structure (Ducrot et al. 1994b, 1994a; Prangé et al. 1995, 1997). X-ray diffraction studies of beticolin microcrystals allowed the determination of the 3-D structure of the molecule (Prangé et al. 1997). Beticolin molecules are no more than $17 \AA$ long (Fig. 1) and, therefore, a multimeric assembly is likely to be necessary to form a pore across a 30 - $\AA$-thick lipid bilayer. It has been shown that, in the presence of $\mathrm{Mg}^{2+}$, a stable and electrically neutral dimer assembles that is composed of two beticolin molecules and two $\mathrm{Mg}^{2+}$ ions (Gomès et al. 1996a). Interestingly, this association with $\mathrm{Mg}^{2+}$ strongly increases partitioning of the toxin into the hydrophobic phase (Mikes et al. 1994b). The 3-D structure of the complex composed of two $\mathrm{B} 1$ molecules and two $\mathrm{Mg}^{2+}$ ions was elucidated by Jalal et al.
(1992). As previously hypothesized for B0 (Goudet et al. 1998), (B-Mg) dimers would be the basic element of the pore.

\section{Common features between beticolin channels.}

A first common feature of beticolin channels is their poor ionic selectivity. Reversal potentials were determined in asymmetrical solutions of $\mathrm{KCl}, \mathrm{NaCl}$, or $\mathrm{LiCl}$. The permeability ratios derived from these data with the GoldmanHodgkin-Katz equation (Table 2) indicated that beticolin channels were poorly selective, as previously reported for B0 channels (Goudet et al. 1998). Cations like $\mathrm{K}^{+}, \mathrm{Na}^{+}$, or $\mathrm{Li}^{+}$are more permeable than $\mathrm{Cl}^{-}$but all these ions have a significant permeability through beticolin channels (Tables 1 and 2).

A second common feature of beticolin channels is their linear current-voltage relationships, whatever the conductance level considered (Fig. 3). The slope conductance is therefore independent of voltage. Ions go through the pore at a rate that is simply proportional to the driving force, and as easily in both directions. These data indicate that (i) channel formation/operation is poorly voltage sensitive and (ii) no intrinsic rectification is enabled as a result of the symmetrical pore structure.

A third common feature of beticolins is their ability to form channels displaying multiple conductance levels. The conductance values derived for the first three conducting states are in a geometric progression of ratio 2: conductance of state

Table 1. Conductance of ortho- and para-beticolins into $200 \mathrm{mM} \mathrm{NaCl}, \mathrm{KCl}$, or $\mathrm{LiCl}$ medium

\begin{tabular}{|c|c|c|c|c|c|c|}
\hline \multirow[b]{2}{*}{ Conductance in different media ${ }^{a}$} & \multicolumn{3}{|c|}{ ortho-beticolins } & \multicolumn{3}{|c|}{ para-beticolins } \\
\hline & B0 & B2 & B4 & B13 & B1 & B3 \\
\hline \multicolumn{7}{|l|}{$\gamma \mathrm{NaCl}$} \\
\hline Level 1 & $8 \pm 0.5(5)$ & $21 \pm 1(3)$ & $11 \pm 0.5$ & $13 \pm 1(4)$ & $29 \pm 1(3)$ & $17 \pm 1(5)$ \\
\hline Level 2 & $17 \pm 1(5)$ & $43 \pm 2(3)$ & $24 \pm 1(3)$ & $26 \pm 2(4)$ & $51 \pm 2(3)$ & $34 \pm 1(5)$ \\
\hline Level 3 & $29 \pm 1(5)$ & $77 \pm 4(3)$ & $48 \pm 2(3)$ & $49 \pm 3(4)$ & $95 \pm 5(3)$ & $60 \pm 2(5)$ \\
\hline \multicolumn{7}{|l|}{$\gamma \mathrm{KCl}$} \\
\hline Level 1 & $11 \pm 0.5$ & $23 \pm 1(3)$ & $11 \pm 0.5$ & $15 \pm 2(5)$ & $28 \pm 1(3)$ & $16 \pm 1(4)$ \\
\hline Level 2 & $23 \pm 1(5)$ & $41 \pm 1(3)$ & $21 \pm 1(3)$ & $31 \pm 4(5)$ & $56 \pm 2(3)$ & $32 \pm 2(4)$ \\
\hline Level 3 & $47 \pm 2(5)$ & $79 \pm 4(3)$ & $41 \pm 2(3)$ & $63 \pm 7(5)$ & $118 \pm 4(3)$ & $57 \pm 2(4)$ \\
\hline \multicolumn{7}{|l|}{$\gamma \mathrm{LiCl}$} \\
\hline Level 1 & $\mathrm{ND}^{\mathrm{b}}$ & $18 \pm 2(2)$ & $11 \pm 0.5(3)$ & ND & $24 \pm 1(3)$ & $16 \pm 1(4)$ \\
\hline Level 2 & ND & $36 \pm 4(2)$ & $25 \pm 1(3)$ & ND & $40 \pm 2(3)$ & $31 \pm 1(4)$ \\
\hline Level 3 & ND & $70 \pm 7(2)$ & $49 \pm 2(3)$ & ND & $80 \pm 2(3)$ & $58 \pm 2(4)$ \\
\hline
\end{tabular}

${ }^{a}$ Conductance values are expressed in $\mathrm{pS}$. Values are mean $\pm \mathrm{SE}$ ( $n$ experiments) measured in symmetrical solutions containing $200 \mathrm{mM} \mathrm{NaCl}, \mathrm{KCl}$, or $\mathrm{LiCl}, 0.44 \mathrm{mM} \mathrm{MgCl} 2,1 \mathrm{mM}$ EDTA, and $10 \mathrm{mM}$ HEPES ( $N$-2-hydroxyethylpiperazine- $N$-2-ethanesulfonic acid)-KOH (free $\mathrm{Mg}^{2+}$ concentration being estimated to be $1 \mu \mathrm{M}$ ).

${ }^{\mathrm{b}}$ Not determined.

Table 2. Ionic selectivity of beticolins channels

\begin{tabular}{|c|c|c|c|c|c|c|}
\hline \multirow[b]{2}{*}{ Permeability $^{\mathrm{a}}$ and conductance ${ }^{\mathrm{b}}$ ratio } & \multicolumn{3}{|c|}{ ortho-beticolins } & \multicolumn{3}{|c|}{ para-beticolins } \\
\hline & B0 & B2 & B4 & B13 & B1 & B3 \\
\hline $\mathrm{PNa} / \mathrm{PK}$ & $0.65 \pm 0.03$ & $0.91 \pm 0.01$ & $2.14 \pm 0.06(4)$ & $\mathrm{ND}^{\mathrm{c}}$ & $0.49 \pm 0.05(2)$ & $2.77 \pm 0.16(4)$ \\
\hline PLi/PK & ND & $0.77 \pm 0.01$ & $1.93 \pm 0.06(3)$ & ND & $0.33 \pm 0.01$ & $2.21 \pm 0.05$ \\
\hline $\mathrm{GNa} / \mathrm{GK}$ & $0.68 \pm 0.05(5)$ & $0.97 \pm 0.05$ & $1.12 \pm 0.04(3)$ & $0.84 \pm 0.04$ & $0.91 \pm 0.09(3)$ & $1.07 \pm 0.01$ \\
\hline GLi/GK & ND & $0.85 \pm 0.05(2)$ & $1.12 \pm 0.07(3)$ & ND & $0.74 \pm 0.06(3)$ & $1.02 \pm 0.02(4)$ \\
\hline
\end{tabular}


two is twice the conductance of state one and conductance of state three is twice the conductance of state two (Table 1). A fourth conductance state is less often observed. This higher conducting state follows this progression (not shown). Two main hypotheses could be envisaged concerning the type of channel structures underlying such a behavior (Meves and Nagy 1989). The first hypothesis is a cluster organization of beticolin elementary channels that would open and close simultaneously, as proposed to explain the multiple conductance states of channels formed by syringomycin E (Kaulin et al. 1998). The second hypothesis is that multiple conductance states of beticolins result from different channel structures, as proposed for channels formed by alamethicin (Bezrukov and Vodyanoy 1993; Vodyanoy et al. 1993). In the case of beticolin channels, the fact that the first three conductance levels display similar ionic selectivity suggests similar pore structure and size, as this would be the case within clusters. With nonelectrolytes of different hydrodynamic sizes, we have demonstrated that the same pore size (pore radius approximately 7.5 $\AA$ ) underlies the first three conductance levels of B3 channels and thereby we have supported the cluster hypothesis (Goudet et al., in press). As ortho-beticolin and para-beticolin channels display similar structural and functional properties, it can be assumed that cluster organization is a common feature of beticolin channels.

Finally, whatever the form of beticolin present at a concentration of $10 \mu \mathrm{M}$, macroscopic currents could be recorded in the presence of high $\mathrm{Mg}^{2+}$ concentration (data not shown, but see Goudet et al. 1998). In the present study, low free $\mathrm{Mg}^{2+}$ concentration $(1 \mu \mathrm{M})$ was used to record reproducibly single channel rather than macroscopic currents. It is therefore concluded that $\mathrm{Mg}^{2+}$ sensitivity is a feature common to all beticolins.

\section{Differences between beticolin channels.}

Although beticolins have similar structures, they differ by the type of isomerization and/or the $R$ residue bridging $\mathrm{C} 11^{\prime}$ and $\mathrm{C} 14^{\prime}$ of the common skeleton (Fig. 1). Since all beticolins seem to form channels with common features, it is worth (i) noting that some functional features differ between channels formed by different beticolins and (ii) discussing how these differences are related to the structural variations in the beticolin family.

As shown in Table 1, whatever the ortho/para pair considered, the para-isomer forms channels with a higher (20 to $30 \%$ ) conductance than that of the channels formed by the ortho-isomer. As discussed above, the $(\mathrm{B}-\mathrm{Mg})_{2}$ dimer is likely to be the basic element forming beticolin channels. The dimer structure forms a trapezoidal frame (Jalal et al. 1992). Here we propose that the hollow at the center of the frame would form the pathway for ions through the structure. From what is known about the molecular shape of ortho- and parabeticolins (Prangé et al. 1997) it can be proposed that parabeticolin dimers make a larger pore than those formed by ortho-beticolin dimers, thus resulting in ion channels with larger conductance.

Despite the fact that $R$ is not believed to line the pore, it is likely to influence the dimer shape and thereby the pore structure. Our data show that the conductance and the ionic selectivity of beticolin channels depend on $R$. For example, B2/B1 form channels with a higher conductance (i.e., pore size) than the others studied (Table 1) and B4/B3 form chan- nels with a different selectivity sequence than the other beticolins studied.

\section{Biological significance.}

A pore radius in the range of $7.5 \AA$ is likely to enable permeation of sugars and amino acids through the plasmic membrane. Ion channel formation by beticolins is thus consistent with previous data indicating that, in plant cells, beticolins induced loss of electrolytes, amino acids, and betacyanine (Macri and Vianello 1979) and depolarized transmembrane potential (Gapillout et al. 1996). Inducing permeabilization of cell membranes is one of the most common killing mechanisms of cytotoxic molecules. Pore formation has been suggested to be responsible for membrane permeabilization, collapse of ionic and electrical gradients, and cell lysis for several peptidic or nonpeptidic toxins or antibiotics: e.g., gramicidin (Woolley and Wallace 1992), alamethicin (Woolley and Wallace 1992; Sansom 1993), phallolysin (Wilmsen et al. 1985), flammutoxin (Tomita et al. 1998), lycotoxin (Yan and Adams 1998), and yeast killer toxins (Kagan 1983). As demonstrated, for example, for necrosis-inducing lipopeptide toxins secreted by the phytopathogenic bacteria Pseudomonas syringae (Hutchison et al. 1995; Feigin et al. 1996; Hutchison and Gross 1997; Bender et al. 1999; Dalla Serra et al. 1999a, 1999b), the ability of beticolins to form ion channels is therefore likely to be involved in the biological activity of these toxins.

\section{MATERIAL AND METHODS}

\section{Beticolins.}

Beticolins were extracted from the mycelium of the $C$. beticola strain $\mathrm{CM}$ and purified as previously described (see Ducrot et al. 1996 and references therein).

\section{Planar lipid bilayer.}

Planar bilayers were formed across a 0.2-mm-diameter hole made in PVDF (polyvinylidene fluoride) septum separating two chambers of $2 \mathrm{ml}$ (defined as cis and trans) by painting a solution of synthetic POPE and POPC (1-palmitoyl-2-oleoylphosphatidylethanolamine and 1-palmitoyl-2-oleoyl-phosphatidylcholine, respectively; Avanti Polar Lipids, Birmingham, $\mathrm{AL})$ in a $1 / 1$ molar ratio dissolved in n-decane $\left(10 \mathrm{mg} \cdot \mathrm{ml}^{-1}\right.$; Sigma, St. Louis, MO) (Mueller et al. 1962).

trans and cis chamber solutions were connected (through 3 $\mathrm{M} \mathrm{KCl} / \mathrm{AgCl} / \mathrm{Ag}$ half-cells) to headstage and signal-ground inputs, respectively, of an Axopatch 200B (Axon Instrument, Foster City, CA) patch-clamp amplifier. Potential values were thus defined as the voltage of trans chamber minus the voltage of cis chamber. Membrane capacitance and resistance monitoring were used to verify membrane formation. Bilayers readily formed with a capacitance of 100 to $150 \mathrm{pF}$. For a period of at least $30 \mathrm{~min}$ prior to toxin addition, those membranes were stable and, in standard solution, had a conductance less than $10 \mathrm{pS}$ at voltages in the $\pm 100 \mathrm{mV}$ range. Recordings were sampled at $2 \mathrm{kHz}$ and filtered at $50 \mathrm{~Hz}$ for further analysis with pClamp 6 (Axon Instrument) and Origin 4.0 (Microcal Software, Northampton, MA) software. To determine unitary amplitude values at a given voltage, amplitude histograms were done and analyzed (Sakhman and Neher 1995). To determine slope conductance $(\gamma)$, these amplitude 
values were plotted against voltage, and conductance was then derived from the slope of current-voltage relationships.

\section{Solutions.}

Standard solutions contained $200 \mathrm{mM} \mathrm{XCl}$ (with $\mathbf{X}=\mathrm{K}, \mathrm{Na}$ or $\mathrm{Li}$ ), $0.44 \mathrm{mM} \mathrm{MgCl}_{2}, 1 \mathrm{mM}$ EDTA, and $10 \mathrm{mM}$ HEPES ( $N$-2-hydroxyethylpiperazine- $N^{\prime}$-2-ethanesulfonic acid)-KOH ( $\mathrm{pH}$ 7.4). The free $\mathrm{Mg}^{2+}$ concentration was estimated to be 1 $\mu \mathrm{M}$. In standard experiments, both the cis and trans chambers contained the above solution.

Asymmetric solutions were used in order to investigate ionic selectivity of beticolin channels. trans medium contained $100 \mathrm{mM} \mathrm{XCl}$ (with $X=\mathrm{K}, \mathrm{Na}$, or Li) whereas cis medium contained $500 \mathrm{mM} \mathrm{XCl}$, the other concentrations being unchanged. Reversal potentials (Erev) in these asymmetric solutions were measured and the cation/anion permeability ratios were then calculated from the Erev values with the Goldman-Hodgkin-Katz equation (Hille 1992).

\section{ACKNOWLEDGMENTS}

This work was supported by grants from Institut National de la Recherche Agronomique and Conseil Régional de Bourgogne to C. G.

\section{LITERATURE CITED}

Balis, C., and Payne, M. G. 1971. Triglycerides and cercosporin from Cercospora beticola: Fungal growth and cercosporin production. Phytopathology 61:1477-1484.

Ballio, A. 1991. Non-host selective fungal phytotoxins: Biochemical aspect of their mode of action. Experimentia 47:783-790.

Bender, C. L., Alarcon-Chaidez, F., and Gross, D. C. 1999. Pseudomonas syringae phytotoxins: Mode of action, regulation, and biosynthesis by peptide and polyketide synthetases. Microbiol. Mol. Biol. Rev. 63:266-292.

Bezrukov, S. M., and Vodyanoy, I. 1993. Probing alamethicin channels with water-soluble polymers. Effect on conductance of channel states. Biophys. J 64:16-25.

Blein, J.-P., Bourdil, I., Rossignol, M., and Scalla, R. 1988. Cercospora beticola toxin inhibits vanadate-sensitive $\mathrm{H}+$ transport in corn root membrane vesicles. Plant Physiol. 88:429-434.

Dalla Serra, M., Bernhart, I., Nordera, P., Di Giorgio, D., Ballio, A., and Menestrina, G. 1999a. Conductive properties and gating of channels formed by syringopeptin 25A, a bioactive lipodepsipeptide from Pseudomonas syringae pv. syringae, in planar lipid membranes. Mol. Plant-Microbe Interact. 12:401-409.

Dalla Serra, M., Fagiuoli, G., Nordera, P., Bernhart, I., Della Volpe, C., Di Giorgio, D., Ballio, A., and Menestrina, G. 1999b. The interaction of lipodepsipeptide toxins from Pseudomonas syringae pv. syringae with biological and model membranes: A comparison of syringotoxin, syringomycin, and two syringopeptins. Mol. Plant-Microbe Interact. 12:391-400.

Daub, M. E. 1982. Cercosporin, a photosensitizing toxin from Cercospora species. Phytopathology 72:370-374.

Daub, M. E., and Ehrenshaft, M. 1993. The photoactivated toxin cercosporin as a tool in fungal photobiology. Physiol. Plant. 89:227-236.

Daub, M. E., and Hangarter, R. P. 1983. Changes in tobacco cell membrane composition and structure caused by the fungal toxin, cercosporin. Plant Physiol. 71:763-766.

Ding, G., Maume, G., Milat, M. L., Humbert, C., Blein, J. P., and Maume, B. F. 1996. Inhibition of cellular growth and steroid 11 betahydroxylation in ras-transformed adrenocortical cells by the fungal toxins beticolins. Cell Biol. Int. 20:523-530.

Dobrowolski, D. C., and Foote, C. S. 1983. Chemistry of singlet oxygen. 46. Quantum yield of cercosporin-sensitized singlet oxygen formation. Angew. Chem. 95:729-730.

Ducrot, P.-H., Einhorn, J., Kerhoas, L., Lallemand, J.-Y., Milat, M.-L., Blein, J.-P., Neuman, A., and Prangé, T. 1996. Cercospora beticola toxins. Part XI. Isolation and structure of Beticolin 0. Tetrahedron
Lett. 37:3121-3124.

Ducrot, P.-H., Lallemand, J.-Y., Milat, M.-L., and Blein, J.-P. 1994a. The yellow toxins produced by Cercospora beticola. Part VIII: Chemical equilibrium between Beticolins; Structure of minor compounds: Beticolin 6 and Beticolin 8. Tetrahedron Lett. 35:8797-8800.

Ducrot, P.-H., Milat, M.-L., Blein, J.-P., and Lallemand, J.-Y. 1994b. The yellow toxins produced by Cercospora beticola. Revised structures of Beticolin 1 and Beticolin 3. J. Chem. Soc. Chem. Commun. pp. 22152216.

Fajola, A. O. 1978. Cercosporin, a phytotoxin from Cercospora spp. Physiol. Plant Pathol. 13:157-164.

Feigin, A. M., Takemoto, J. Y., Wangspa, R., Teeter, J. H., and Brand, J. G. 1996. Properties of voltage-gated ion channels formed by syringomycin E in planar lipid bilayers. J. Membr. Biol. 149:41-47.

Gapillout, I., Mikes, V., Milat, M.-L., Simon-Plas, F., Pugin, A., and Blein, J.-P. 1996. Cercospora beticola toxins. Use of fluorescent cyanine dye to study the effects on tobacco cell suspensions. Phytochemistry 43:387-392.

Gomès, E., Gordon-Weeks, R., Simon-Plas, F., Pugin, A., Milat, M. L., Leigh, R. A., and Blein, J. P. 1996a. Cercospora beticola toxins. Part XVII. The role of the beticolin/Mg2+ complexes in their biological activity. Study of plasma membrane $\mathrm{H}(+)$-ATPase, vacuolar $\mathrm{H}(+)-$ PPase, alkaline and acid phosphatases. Biochim. Biophys. Acta 1285: 38-46.

Gomès, E., Simon-Plas, F., Milat, M.-L., Gapillout, I., Mikès, V., Pugin, A., and Blein, J.-P. 1996b. Cercospora beticola toxins. IX. Relationship between structure of beticolins, inhibition of plasma membrane H+-ATPase and partition in lipid membranes. Physiol. Plant. 98:133139.

Goudet, C., Benitah, J.-P., Milat, M.-L., Sentenac, H., and Thibaud, J.-B. Cluster organization and pore structure of ion channels formed by beticolin 3, a non-peptidic fungal toxin. Biophys. J. (In press.)

Goudet, C., Véry, A.-A., Milat, M.-L., Ildefonse, M., Thibaud, J.-B., Sentenac, H., and Blein, J.-P. 1998. Magnesium ions promote assembly of channel-like structures from beticolin 0, a non-peptide fungal toxin purified from Cercospora beticola. Plant J. 14:359-364.

Hartman, P. E., Dixon, W. J., Dahl, T. A., and Daub, M. E. 1988. Multiple modes of photodynamic action by cercosporin. Photochem. Photobiol. 47:699-703.

Hille, B. 1992. Ionic Channels of Excitable Membranes. Sinauer Associates, Sunderland, MA.

Hutchison, M. L., and Gross, D. C. 1997. Lipopeptide phytotoxins produced by Pseudomonas syringae pv. syringae: Comparison of the biosurfactant and ion channel-forming activities of syringopeptin and syringomycin. Mol. Plant-Microbe Interact. 10:347-354.

Hutchison, M. L., Tester, M. A., and Gross, D. C. 1995. Role of biosurfactant and ion channel-forming activities of syringomycin in transmembrane ion flux: A model for the mechanism of action in the plantpathogen interaction. Mol. Plant-Microbe Interact. 8:610-620.

Jalal, M. A. F., Hossain, M. B., Robeson, D. J., and van der Helm, D. 1992. Cercospora beticola phytotoxins: Cebetins that are photoactive, $\mathrm{Mg}^{2+}$-binding, chlorinated anthraquinone-xanthone conjugates. J. Am. Chem. Soc. 114:5967-5971.

Kagan, B. L. 1983. Mode of action of yeast killer toxins: Channel formation in lipid bilayer membranes. Nature 302:709-711.

Kagan, B. L., and Sokolov, Y. 1994. Use of lipid bilayer membranes to detect pore formation by toxins. Methods Enzymol. 235:691-705.

Kaulin, Y. A., Schagina, L. V., Bezrukov, S. M., Malev, V. V., Feigin, A. M., Takemoto, J. Y., Teeter, J. H., and Brand, J. G. 1998. Cluster organization of ion channels formed by the antibiotic syringomycin $\mathrm{E}$ in bilayer lipid membranes. Biophys. J. 74:2918-2925.

Knox, J. P., and Dodge, A. D. 1985. Singlet oxygen and plants. Phytochemistry 24:889-896.

Lousberg, R. J. C. C., Weiss, U., Salemink, C. A., Arnone, A., Merlini, L., and Nasini, G. 1971. The structure of cercosporin, a naturally occurring quinone. J. Chem. Soc. Chem. Commun. pp. 1463-1464.

Macri, F., Dell' Antone, P., and Vianello, A. 1983. ATP-dependent proton uptake inhibited by Cercospora beticola toxin in pea stem microsomal vesicle. Plant Cell Environ. 6:555-558.

Macri, F., and Vianello, A. 1979. Inhibition of K+ uptake, H+ extrusion and $\mathrm{K}+$ activated ATPase, and depolarization of transmembrane potential in plant tissues treated with Cercospora beticola. Physiol. Plant Pathol. 15:161-170.

Meves, H., and Nagy, K. 1989. Multiple conductance states of the so- 
dium channel and of other ion channels. Biochim. Biophys. Acta 988: 99-105.

Mikes, V., Lavernet, S., Milat, M.-L., Collange, E., Paris, M., and Blein, J.-P. 1994a. Cercospora beticola toxins. Part VI: Preliminary studies of protonation and complexation equilibria. Biophys. Chem. 52:259265.

Mikes, V., Milat, M.-L., Pugin, A., and Blein, J.-P. 1994b. Cercospora beticola toxins. VII. Fluorometric study of their interactions with biological membranes. Biochim. Biophys. Acta 1195:124-130.

Milat, M.-L., Prangé, T., Ducrot, P.-H., Tabet, J.-C., Einhorn, J., Blein, J.-P., and Lallemand, J. Y. 1992. Structures of the Beticolins, the yellow toxins produced by Cercospora beticola. J. Am. Chem. Soc. 114: 1478-1479.

Mueller, P., Rudin, D. O., Tien, H. T., and Wescott, W. C. 1962. Reconstitution of cell membrane structure in vitro and its transformation into an excitable system. Nature 194:979-980.

Prangé, T., Neuman, A., Milat, M.-L., and Blein, J.-P. 1995. The yellow toxins produced by Cercospora beticola. V. Structure of Beticolin 2 and 4. Acta Crystallogr. B51:308-314.

Prangé, T., Neuman, A., Milat, M.-L., and Blein, J.-P. 1997. Cercospora beticola toxins. Part 16. X-ray diffraction analyses on microcrystals of three $p$-beticolins. J. Chem. Soc. Perkins Trans. 2:1819-1825.

Rustérucci, C., Milat, M.-L., and Blein, J.-P. 1996. Cercospora beticola toxins. Determination of O2- scavenging activity of Beticolin 1. Phytochemistry 42:979-983
Sakhman, B., and Neher, E. 1995. Single-Channel Recording. Plenum, New York.

Sansom, M. S. 1993. Alamethicin and related peptaibols - model ion channels. Eur. Biophys. J. 22:105-124.

Schlösser, E. 1962. Uber eine biologisch aktive Substanz aus Cercospora beticola. Phytopathol. Z. 44:295-312.

Schlösser, E. 1971. The Cercospora beticola toxin. Phytopathol. Mediterr. 10:154-158.

Tomita, T., Ishikawa, D., Noguchi, T., Katayama, E., and Hashimoto, Y. 1998. Assembly of flammutoxin, a cytolytic protein from the edible mushroom Flammulina velutipes, into a pore-forming ring-shaped oligomer on the target cell. Biochem. J. 333:129-137.

Vodyanoy, I., Bezrukov, S. M., and Parsegian, V. A. 1993. Probing alamethicin channels with water-soluble polymers. Size-modulated osmotic action. Biophys. J. 65:2097-2105.

Wilmsen, H. U., Faulstich, H., Eibl, H., and Boheim, G. 1985. Phallolysin. A mushroom toxin, forms proton and voltage gated membrane channels. Eur. Biophys. J. 12:199-209.

Woolley, G. A., and Wallace, B. A. 1992. Model ion channels: Gramicidin and alamethicin. J. Membr. Biol. 129:109-136.

Yamazaki, S., and Ogawa, T. 1972. The chemistry and stereochemistry of cercosporin. Agric. Biol. Chem. 36:1707-1718.

Yan, L., and Adams, M. E. 1998. Lycotoxins, antimicrobial peptides from venom of the wolf spider Lycosa carolinensis. J. Biol. Chem. 273:2059-2066. 